\title{
Synchronous spawning of Acropora in the Red Sea
}
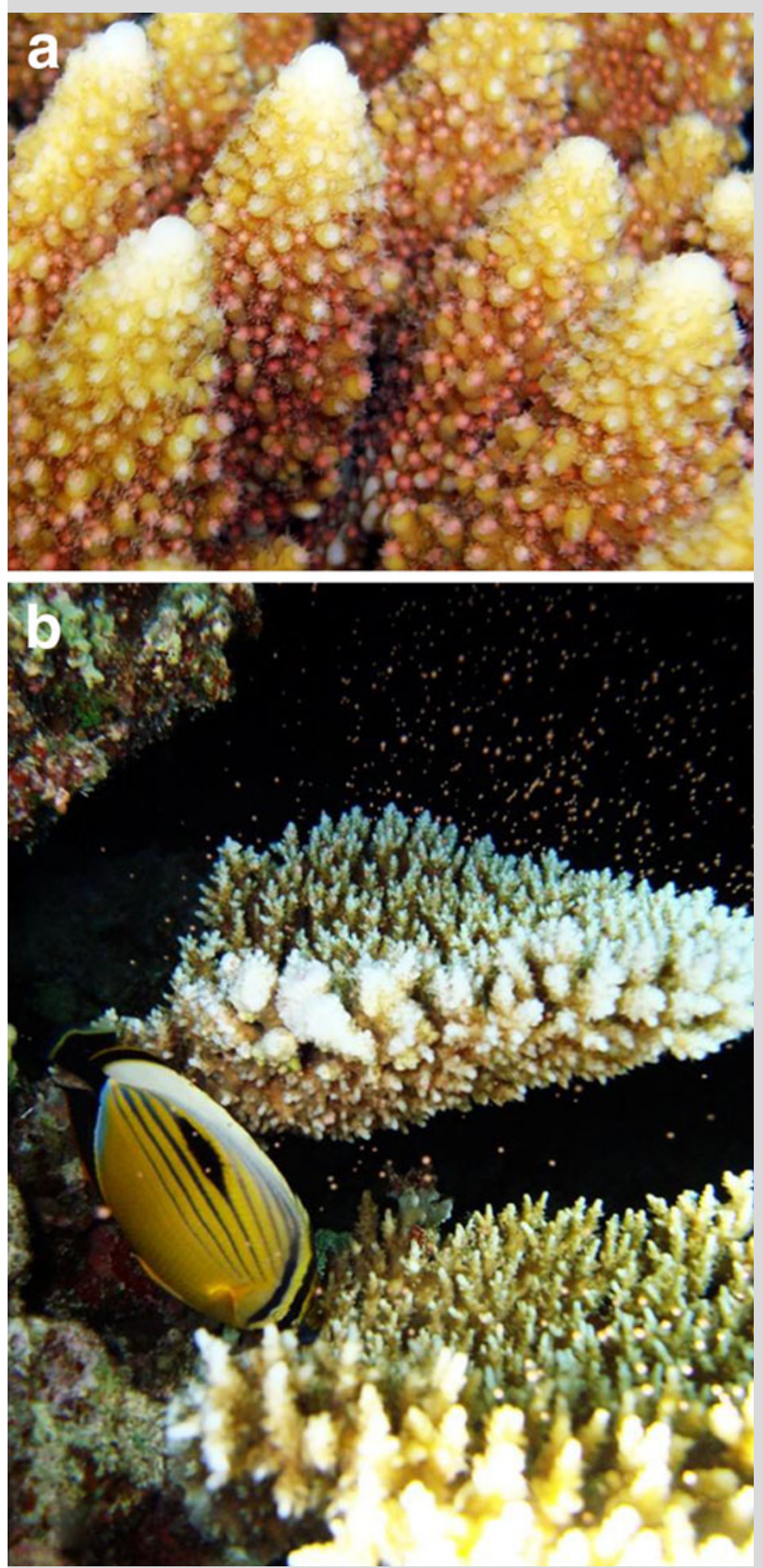

Fig. 1 a Setting of gamete bundles in Acropora gemmifera, b Chaetodon austriacus feeding on egg-sperm bundles released from Acropora lamarcki
Multi-specific synchronous spawning is a reproductive strategy used by scleractinian corals that has now been described from coral reefs in 23 locations globally (Baird et al. 2009). While high multi-specific synchrony in the reproductive condition of Acropora colonies has been documented in the Red Sea in April and/or May (Hanafy et al. 2010), multi-specific synchronous spawning has not been directly observed. In April 2011, mature oocytes were found in a high proportion of colonies in numerous species of Acropora on reefs near Thuwal, Saudi Arabia $\left(22^{\circ} 18^{\prime} 19.26^{\prime \prime} \mathrm{N}, 38^{\circ} 57^{\prime} 56.66^{\prime \prime} \mathrm{E}\right)$. On the night of April 16 2011, two nights before the full moon, egg-sperm bundles were first observed in Acropora polyps at $20: 30 \mathrm{~h}$ (Fig. 1a). Between 22:30 and 23:45 h, 43 colonies from 10 out of 13 surveyed Acropora species released egg/sperm bundles (Fig. 1b), including three species that had not been observed to spawn previously (A. plantaginea, A. parapharaonis, and A. lamarcki). This is the first documented multi-specific synchronous spawning event in the Red Sea, demonstrating that the asynchronous spawning pattern at Eilat in the Gulf of Aqaba (Shlesinger and Loya 1985) is not representative of the Red Sea, and providing further support for the prediction that these events are characteristic of all speciose coral assemblages (Guest et al. 2005).

Acknowledgments The authors would like to thank AH Baird for his assistance in Acropora taxonomy.

\section{References}

Baird AH, Guest JR, Willis BL (2009) Systematic and biogeographical patterns in the reproductive biology of scleractinian corals. Ann Rev Ecol Evol Sys 40:551-571 Guest JR, Baird AH, Goh BPL, Chou LM (2005) Seasonal reproduction in equatorial reef corals. Invertebr Reprod Dev 48:207-218

Hanafy MH, Aamer MA, Habib AB, Baird AH (2010) Synchronous reproduction of corals in the Red Sea. Coral Reefs 29:119-124 Shlesinger Y, Loya Y (1985) Coral community reproductive patterns: Red Sea versus the Great Barrier Reef. Science 228:1333-1335

\section{J. Bouwmeester $(\bowtie) \cdot$ M. T. Khalil $\cdot$ P. De La} Torre $\cdot$ M. L. Berumen

Red Sea Research Center, King Abdullah University of Science and Technology, Thuwal, Kingdom of Saudi Arabia e-mail: jessica.bouwmeester@kaust.edu.sa

\section{L. Berumen}

Biology Department, Woods Hole Oceanographic Institution, Woods Hole, MA 02543, USA 